Hydrol. Earth Syst. Sci., 14, 2671-2679, 2010

www.hydrol-earth-syst-sci.net/14/2671/2010/

doi: 10.5194/hess-14-2671-2010

(C) Author(s) 2010. CC Attribution 3.0 License.

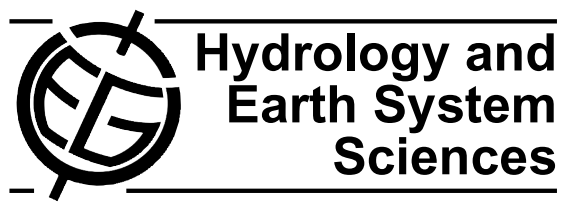

\title{
Investigating changes over time of annual rainfall in Zimbabwe
}

\author{
D. Mazvimavi \\ Institute for Water Studies, University of the Western Cape, Private Bag X17, Bellville, 7535, South Africa \\ Received: 30 May 2008 - Published in Hydrol. Earth Syst. Sci. Discuss.: 10 July 2008 \\ Revised: 15 November 2010 - Accepted: 15 December 2010 - Published: 22 December 2010
}

\begin{abstract}
There is increasing concern in southern Africa about the possible decline of rainfall as a result of global warming. Some studies concluded that average rainfall in Zimbabwe had declined by $10 \%$ or $100 \mathrm{~mm}$ during the last 100 years. This paper investigates the validity of the assumption that rainfall is declining in Zimbabwe. Time series of annual rainfall, and total rainfall for (a) the early part of the rainy season, October-November-December (OND), and (b) the mid to end of the rainy season, January-FebruaryMarch (JFM) are analysed for the presence of trends using the Mann-Kendall test, and for the decline or increase during years with either high or low rainfall using quantile regression analysis. The Pettitt test has also been utilized to examine the possible existence of change or break-points in the rainfall time series. The analysis has been done for 40 rainfall stations with records starting during the 1892 1940 period and ending in 2000, and representative of all the rainfall regions.

The Mann-Kendal test did not identify a significant trend at all the 40 stations, and therefore there is no proof that the average rainfall at each of these stations has changed. Quantile regression analysis revealed a decline in annual rainfall less than the tenth percentile at only one station, and increasing of rainfall greater than the ninetieth percentile at another station. All the other stations had no changes over time in both the low and high rainfall at the annual interval. Climate change effects are therefore not yet statistically significant within time series of total seasonal and annual rainfall in Zimbabwe. The general perception about declining rainfall is likely due to the presence of multidecadal variability characterized by bunching of years with above (e.g. 19511958, 1973-1980) and below (e.g. 1959-1972, 1982-1994) average rainfall.
\end{abstract}

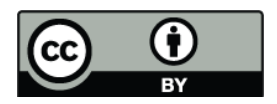

Correspondence to: D. Mazvimavi (dmazvimavi@uwc.ac.za)

\section{Introduction}

There are several instances when the occurrences of floods or droughts in southern Africa are considered as evidence of effects of climate change due to increased emissions of greenhouse gases. Some studies concluded that rainfall had decreased in Zimbabwe due to global warming. For example, Unganai (1996) suggested that areal annual rainfall in Zimbabwe had declined by $10 \%$ between 1900 and 1994; and Makarau (1995) made a similar observation. Mason and Jury (1997) suggested that there was some evidence of desiccation and increased rainfall variability. Chamaille-Jammes et al. (2007) carried out quantile regression of rainfall at three stations in north-western Zimbabwe and concluded that rainfall during years with below average rainfall was declining at two stations, and this was attributed to global warming. Van Wageningen and du Plessis (2007) made a similar conclusion regarding the 1961-2003 rainfall for Cape Town, South Africa. If these conclusions are valid, then planning and management of water resources systems have to adapt to the change of rainfall.

The decline in rainfall over the years as concluded by Makarau (1995), Unganai (1996), and Chamaille-Jammes et al. (2007) has however not been established in other studies carried out in Zimbabwe and other parts of Africa. Nicholson (2000) noted that multidecadal variations of rainfall during the 1950-1989 period were similar to variations that occurred during the nineteenth century. Hulme et al. (2001) and Faucherean et al. (2003) did not find evidence of progressive desiccation in Africa. The presence of cyclic behaviour in southern African rainfall (Tyson, 1986), and the linkages between rainfall and El Nino events (Mason and Jury, 1997; Nicholson, 2000; Nash and Endfield, 2008) are considered to explain partly the occurrence of droughts. What is uncertain is whether the general perception about the progressive desiccation in Zimbabwe is valid. Nash and Endfield (2002) noted that perceptions about the increasing severity

Published by Copernicus Publications on behalf of the European Geosciences Union. 
of droughts are often influenced by the tendency for humans to compare recent drought years to previous wet periods during their lifetimes. Thus perceptions about droughts increasing in their frequencies and severity in Zimbabwe may be due to a comparison of the dry 1980's and 1990's to the wet 1970's. The decline in agricultural output in Zimbabe during the 2000's was suggested as evidence for increasing frequency and severity of droughts, but Richardson (2007) was of the view that this decline was mainly due to inappropriate government policies.

Previous studies (Makarau, 1995; Unganai, 1996) investigating the possible decline of rainfall in Zimbabwe used linear regression which reflects changes around the mean value. Climate change effects may be noticeable through changes in the mean, or the variability of rainfall. New et al. (2006) established that changes of daily temperatures during the 1961 to 2000 period were much more evident in the tails of the distributions (hot and cold days) than in the average temperatures of stations in west and southern Africa. A study that examines possible changes over time of rainfall during years with low and high rainfall will contribute towards the development of appropriate adaptation measures for such changes (Aguilar et al., 2009). This paper investigates the presence or absence of change points or trends in the rainfall received during (a) the early part of the wet season, (b) mid to end of the season, and (c) at the annual level. New et al. (2006) and Aguilar et al. (2009) highlighted that some changes in rainfall over time may not be detectable at the annual interval, hence this study is also examining rainfall at the sub-annual interval. The outputs of this study will assist agricultural and water resources planners and managers to determine whether current problems of water availability are due to effects of natural climate variability, effects of enhanced greenhouse effects, or poor water resources management practices.

\section{Material and methods}

The annual time series investigated are the total rainfall for (a) the early part of the rainy season, October-NovemberDecember (OND), (b) middle to end of the rainy season, January-February-March (JFM), and (c) the whole year. The sub-annual rainfall times series have been selected since some changes may not be detectable in the total annual rainfall. Rainfed crop production in Zimbabwe is done during the October to April period. Planting of most crops is done during the October to December period. Thus changes of the OND rainfall will affect the early stages of crop development, while changes of the JFM rainfall will affect the late stages of plant development. Thus the OND and JFM periods were selected as they are critical for rainfed crop production. Annual and monthly rainfall data for 40 stations with records starting during the 1892 to 1941 period, and ending in 2000 have been used in this study (Fig. 1). The stations were selected in order to represent all the rainfall regions in
Zimbabwe. These rainfall regions were identified by Unganai and Mason (2001) who did principal component and cluster analysis of rainfall for several locations throughout the country. The regions reflect the influence of the moisture bearing airstreams from the north-west (Congo Air), northeast, and the south easterlies on the spatial patterns of rainfall. Elevation does also affect rainfall distribution in Zimbabwe. The stations selected had data that had been quality controlled by the Department of Meteorological Services using the standard methods recommended by the World Meteorological Organization (WMO). Tyson (1986) identified an 18-20 year cycle in time series of annual rainfall for parts of southern Africa including Zimbabwe. The presence of cyclic behaviour or multidecadal variability in a short time series can be mistaken for a trend. Rainfall stations with over 60 years of data were therefore selected in order to minimize the risk of any cyclic behaviour being identified as a trend. Rainfall data for the period after the year 2000 was not readily available for some of the stations, and therefore the period of record considered in this study was up to the year 2000 .

Changes in rainfall over time have the potential to change the median rainfall or introduce a trend. Therefore, statistical tests for determining a change in the median rainfall and the presence of a trend were used in this study. The Pettitt test for detecting changes in the median was used for this purpose. A description of this test is given in several references (Pettitt, 1979; Nechval and Nechval, 2000; Kundzewicz and Robson, 2004; Mazvimavi and Wolski, 2006) and is not repeated in this paper. Nechval and Nechval (2000) modified this test so that the location within a time series of the change point is identifiable. The non-parametric Mann-Kendall test which is capable of detecting both linear and non-linear trends (Kendall, 1976; Kundzewicz, 2004; Kundzewicz and Robson 2004) has been used in this study. Both the Pettitt test and Man-Kendal test have been used in other studies investigating possible changes in rainfall over Africa (New et al., 2006; Conway et al., 2008).

This paper hypothesizes that climate change may or could have caused changes to rainfall received during years with high or low rainfall and these changes may not equally affect all the percentile values of annual rainfall. The assessment of whether climate change has affected rainfall should therefore cover different percentile values. The WMO Joint Expert Team on Climate Change Detection and Indices (ETTCCDI) has used this concept to derive some of the climate change indices, e.g. percentage days when minimum (maximum) daily temperature is below (above) the 10th (90th) percentile, annual total precipitation for days with precipitation greater than the 95th or 99th percentile (available at: http://cccma.seos.uvic.ca/ETCCDI/list_27_indices.shtml, 2010). This study used quantile regression to establish the presence of linear or non-linear trends for selected percentiles of seasonal and annual rainfall. The 70th, 80th and 90th percentiles were considered to reflect high rainfall, while the 10th, 20th and 30th percentiles were for 


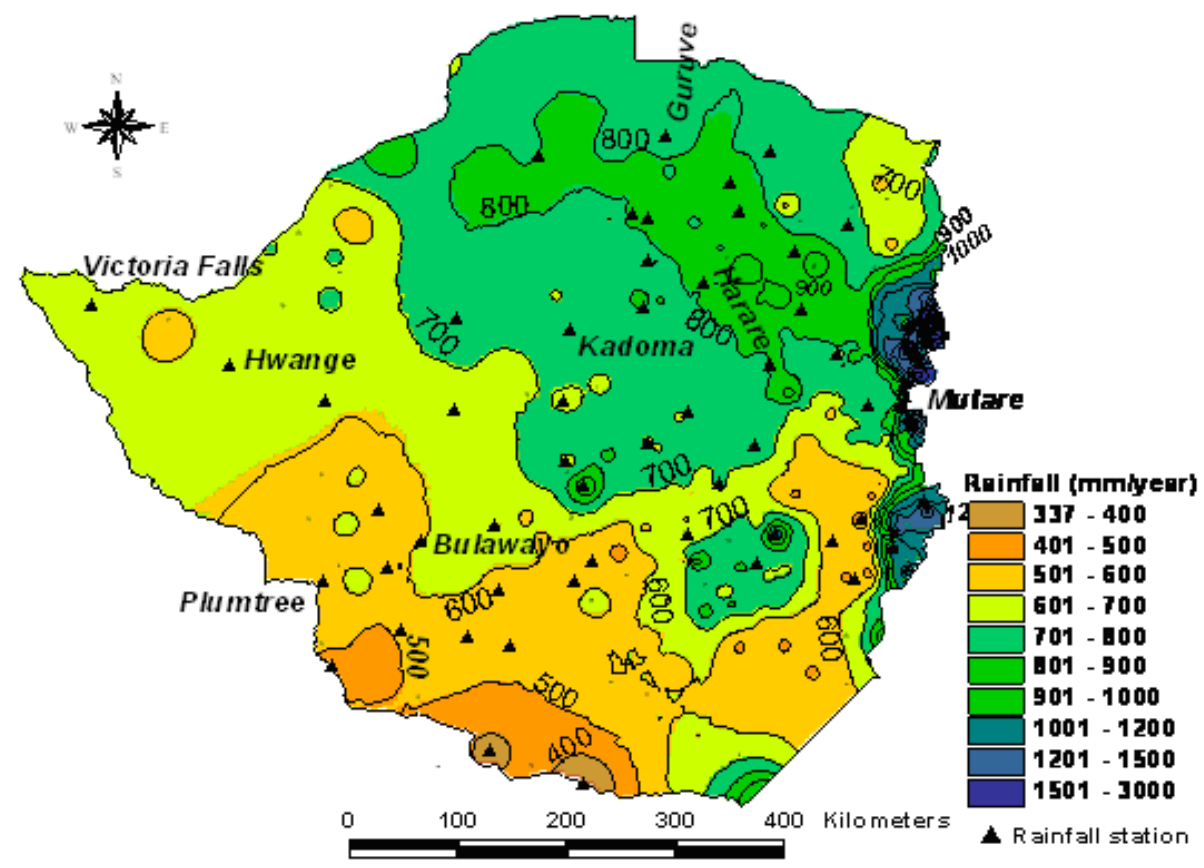

Fig. 1. Location of the 40 stations selected for analysis and the spatial variation of average annual rainfall in Zimbabwe.

low rainfall. Quantile regression which was developed by Koenker and Basset (1978) is capable of identifying changes over time of any percentile value. Chamaille-Jammes et al. (2007) used the same method to investigate whether annual rainfall had changed over time. A full description of the quantile regression technique is given in Koenker and Basset, (1978), Buchinsky (1998), Koenker and Hallock (2001), Cade and Noon (2003), and Yu et al. (2003). In this method, we let $Y$ be a random variable which is the time series of annual rainfall, and $\theta$ with values in the $0 \leq \theta \leq 1$ range is the probability of $Y$ being less than or equal to $\tau$. Therefore $\tau$ is the $\theta$ th quantile or percentile of $Y$. We define $X$ as a covariate of $Y$, and $\tau$ or $Y(\theta \mid \mathrm{x})$ is the $\theta$ th conditional quantile of $Y$ given that $X=x$. Then the first order quantile regression model relating $Y(\theta \mid \mathrm{x})$ to $X$ has the following form;

$Y(\theta \mid x)=\beta(\theta)_{0}+\beta(\theta)_{1} X+\xi$

where $\beta(\theta)_{0}$ is the intercept, $\beta(\theta)_{1}$ is the slope coefficient and both vary depending on the value of $\theta$ th quantile or percentile being considered. $\xi$ is the error with the expectation of zero. The $\theta$ th quantile regression estimate is obtained by minimizing the following function (Koenker and Basset, 1978; Buchinsky, 1998);

$\operatorname{minimize} \frac{1}{n}\left\{\sum_{i: y \geq x_{i} \beta} \theta\left|y_{i}-x_{i} \beta\right|+\sum_{i: y_{i}\left\langle x_{i} \beta\right.}(1-\theta)\left|y_{i}-x_{i} \beta\right|\right\}$

where $n=$ sample size, $i=1,2, \ldots, n, y_{i}=$ value of random variable $Y, x_{i}=$ value of random variable $X$. Koenker (2006) developed the software, "quantreg", written in R language for undertaking quantile regression and is available for downloading from http://www.r-project.org/. The parameters of the quantile regression model, which are the intercept and slope coefficients in Eq. (1) are estimated using the rank inverse method. Standard errors, confidence intervals, $t$ statistics, and $p$-values for these coefficients are also estimated by this software package.

For the purpose of detecting the presence or absence of trends of quantiles of OND, JFM, and annual rainfall, $X$ is the year of record in this study. A $\beta(\theta)_{1}$ that is negative (positive) and significantly different from zero is an indication that the $\theta$ th quantile of rainfall is decreasing (increasing). For each rainfall station, the 10th, 20th, and 30th percentiles were considered to be indicators of low rainfall, while the 70th, 80th, and 90th percentiles were regarded as indicators of high rainfall. If the slope coefficient was significantly different from zero at the $5.0 \%$ significance level, this was considered as evidence of the decline or increase of rainfall. The quantreg software can derive intercepts and slope coefficients for any $\theta$ value at each station. Quantile regression has the desirable attribute of being able to describe responses of both homoscedastic and heteroscedastic variables. If the dependent variable is homoscedastic, the slope parameter, $\beta(\theta)_{1}$, is constant for all quantiles (Fig. 2). For a heteroscedastic dependent variable, the slope parameter, $\beta(\theta)_{1}$, differs for different quantiles $(\theta)$ (Fig. 2). 

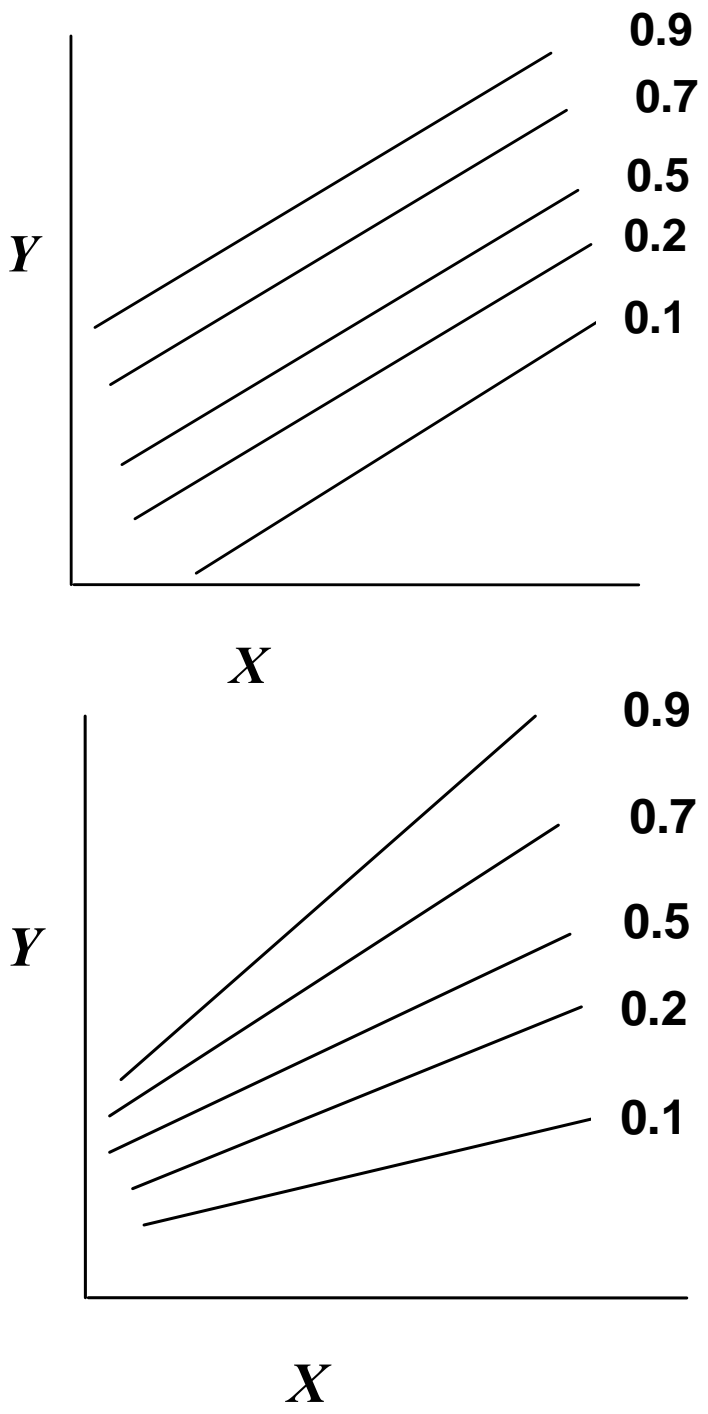

Fig. 2. Quantile regression is capable of modelling a homoscedastic relationship (top graph) with constant slope coefficient, $\beta(\theta) 1$, for all quantile values, and a heteroscedastic relationship which has different values of the slope coefficient for different quantile values. The plotted lines show relationships for the $0.1,0.2,0.5,0.7$, and 0.9 quantiles.

\section{Results and discussion}

Average annual rainfall $(\bar{P})$ at the selected stations varies from $337 \mathrm{~mm}$ year $^{-1}$ in the extreme southern part of the country to $1110 \mathrm{~mm} \mathrm{year}^{-1}$ on the Eastern Highlands located along the eastern border of Zimbabwe and Mozambique (Fig. 1). Annual rainfall has high inter-annual variability (Fig. 3), with the coefficient of variation being $23 \%$ to $40 \%$. Figure 3 also shows the tendency for bunching of years with generally above average (e.g. 1951-1958, 19731980) and below average (e.g. 1959-1970, 1982-1994). The annual rainfall at all the stations has however no significant
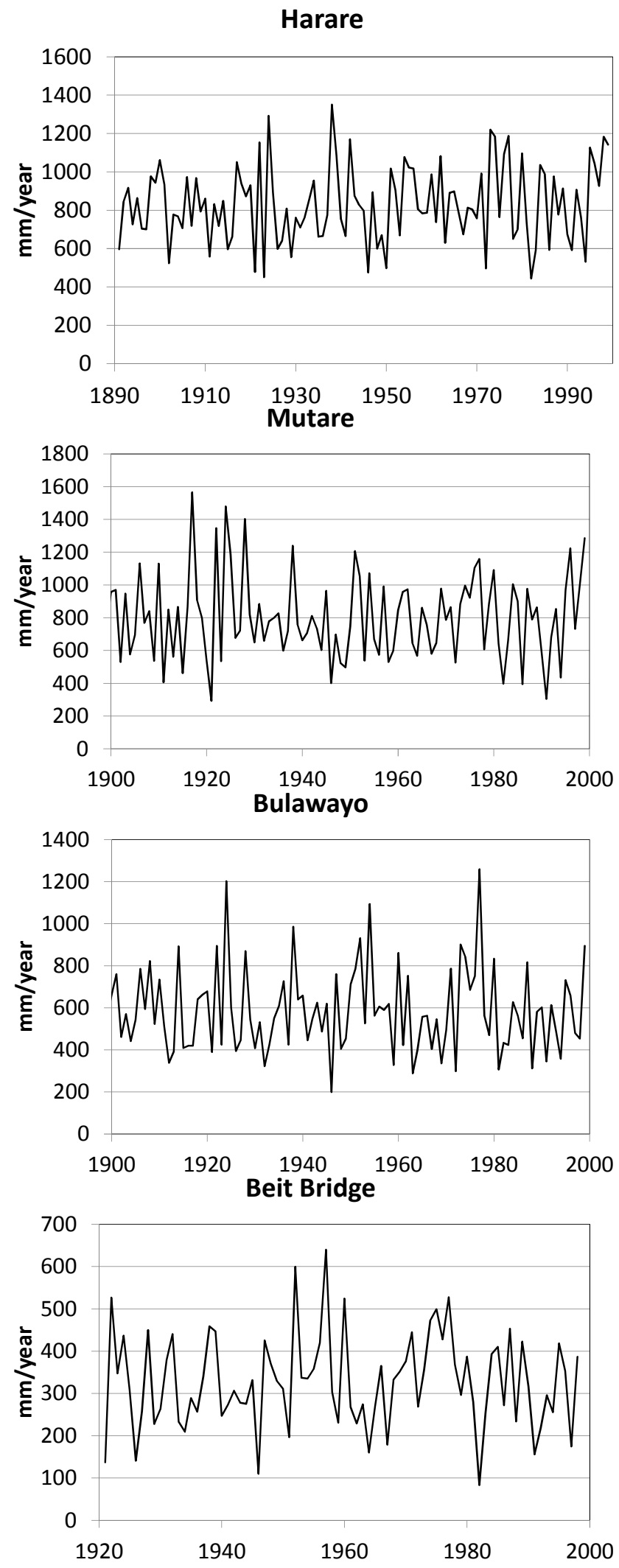

Fig. 3. Variation of annual rainfall for Harare $\left(\bar{P}=830 \mathrm{~mm} \mathrm{year}^{-1}\right)$ in the northern central part, Mutare $\left(\bar{P}=801 \mathrm{~mm}\right.$ year $\left.^{-1}\right)$ in the Eastern Highland, Bulawayo $\left(\bar{P} \mathrm{~m}=587 \mathrm{~mm}_{\text {year }}{ }^{-1}\right)$ in the west, and Beit Bridge $\left(\bar{P}=337\right.$ mm year $\left.^{-1}\right)$ in the southern most part. 
Table 1. Record lengths at stations selected for analysis with records beginning during the 1892 to 1941 period and ending in 2000.

\begin{tabular}{rr}
\hline Record Length (Years) & No. of Stations \\
\hline $60-70$ & 1 \\
$71-80$ & 7 \\
$81-90$ & 11 \\
$91-100$ & 15 \\
$101-109$ & 6 \\
\hline Total & 40 \\
\hline
\end{tabular}

autocorrelation even for lags up to 20 years. Over $86 \%$ of the selected stations have rainfall data longer than 61 years, while $40 \%$ of the stations have over 100 years of data (Table 1).

The Pettitt test identified significant change points or change of the median of the OND rainfall at three out of the 40 stations (Fig. 4). These change points were identified for the 1946/1947 season at two stations (Plumtree, Kezi) located on the western part, and in 1986/1987 for a northern station (Banket). Conway et al. (2008) also found a change point occurring in 1945 for the annual rainfall at Victoria Falls which is in the northwest. Significant change points for the JFM rainfall were identified at six stations with four of these being located on the eastern part of the country (Fig. 4). These change points have been identified for different years with the exception of two stations. The occurrence of change points in different years suggests that these changes are not due to a regional change of physical processes responsible for rainfall formation such as the atmospheric circulations. These change points could be due to changes in the exposure of rain gauges (Stott, et al., 2010). No significant change points in annual rainfall were identified except for three stations for the following periods 1926/1927, 1980/1981, 1994/1995 (Fig. 4). Stations for which change points have been identified in the OND, JFM, and in annual rainfall time series, are not located in geographically contiguous areas, while neighbouring stations do not have similar changes in the median. The change points have been identified at few stations, 7 to $14 \%$ of the total number of stations analysed which raises doubts about the physical significance of these changes.

The Mann-Kendall test did not identify any trend in the OND, and annual time series. A significant trend was identified in the JFM time series at two out of 40 stations. Aguilar et al. (2009) also found no significant trend in several rainfall indices derived from daily rainfall including the total annual precipitation at stations in Zimbabwe. Similarly, New et al. (2006) found that very few stations in 14 African countries studied had statistically significant trends in their rainfall. The lack of trends in rainfall time series does not support

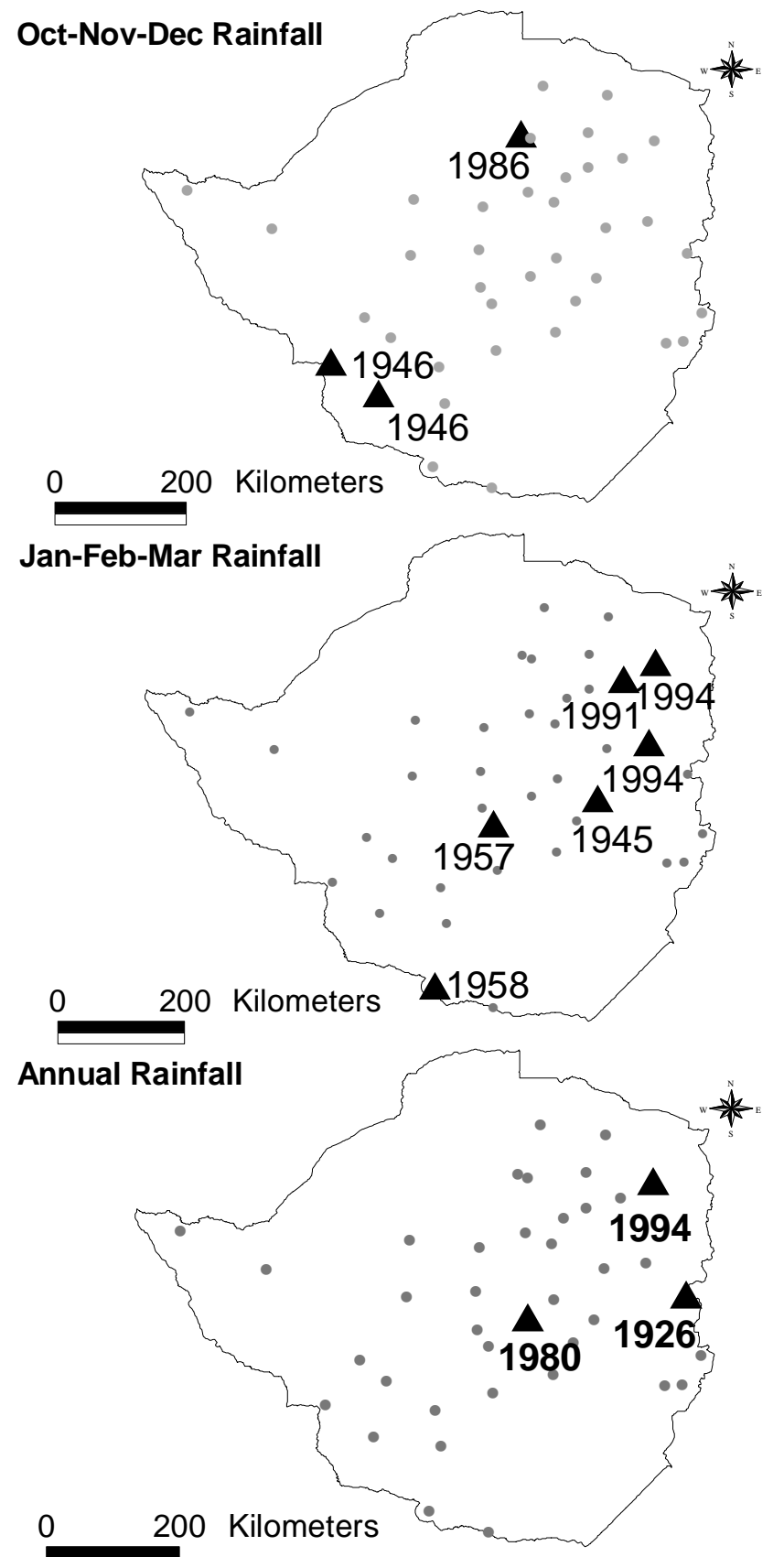

Fig. 4. Location of stations (triangles) where change points were identified and the year for which this change occurred is shown adjacent to the station.

the conclusion that annual rainfall in Zimbabwe had decline by $10 \%$ between 1900 and 1994 (Unganai, 1996) or $100 \mathrm{~mm}$ from 1900 to 1992 (Makarau, 1995). Unganai and Makarau made this conclusion after analysing data that were then available up to 1994 and 1992 respectively. Both authors did not state the statistical significance level they used when arriving at these conclusions. It seems that the period of record 

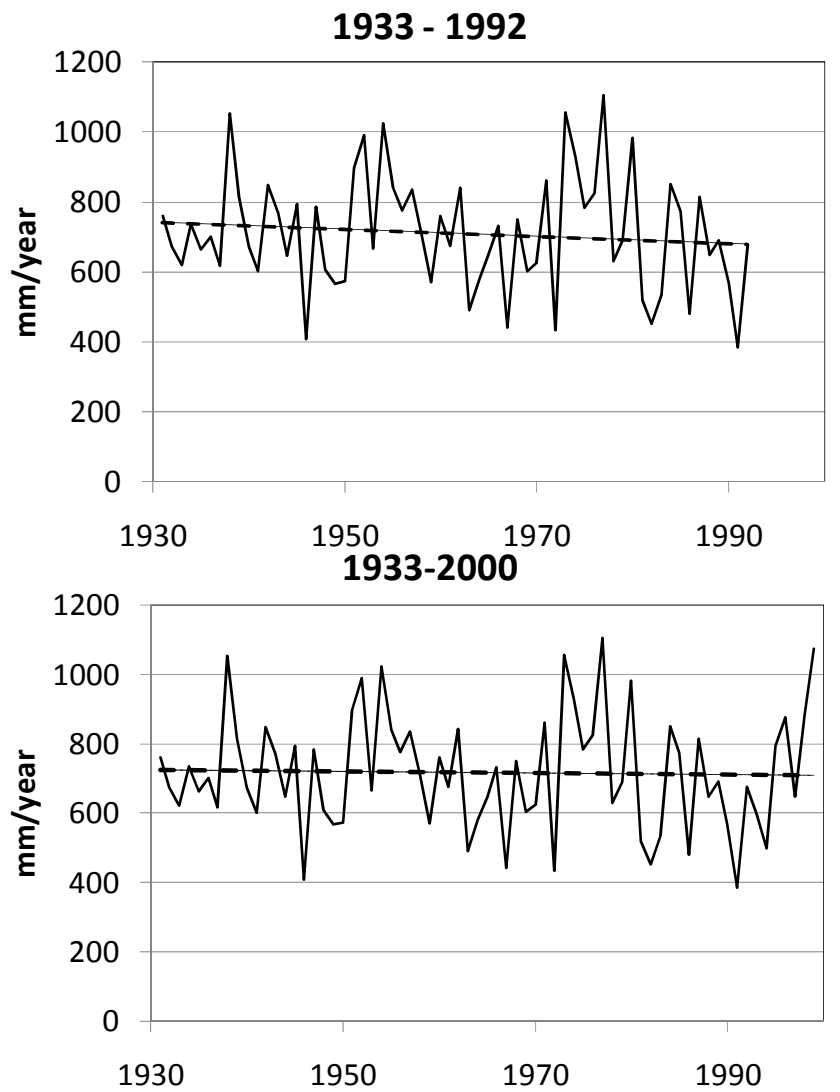

Fig. 5. Trend analysis of annual areal rainfall for Zimbabwe for the 1933-1992 and 1933-2000 period. The 1933-1992 period trend line is described by $Y=772.6-1.01 X\left(r^{2}=0.01\right)$ while the 19332000 period trend line is $Y=729.8-0.20 X\left(r^{2}=0.0\right)$.

used influenced the result obtained. Figure 5 shows a trend analysis done using linear regression of average annual rainfall for the whole country based on the period up to 1992 as was done by Makarau, and up to 2000. Based on the 19331992 data the relationship between annual rainfall and year of record is

$Y=772.6-1.01 X \quad r^{2}=0.01$

Using the 1933-2000 data the relationship is

$Y=729.8-0.20 X \quad r^{2}=0.00$

where $Y=$ average annual rainfall for Zimbabwe based on the 40 stations used in this study, $X=$ number of years since 1900 following the definition of $X$ in the Makarau study, $r^{2}=$ coefficient of determination.

The slope coefficient in Eq. (3) has a value approximating that obtained by Makarau (0.8). The decline of areal annual rainfall that both Makarau and Unganai observed was heavily influenced by the low rainfall received during the 1982 to 1994 period. After this period, high rainfall was experienced resulting in the decline no longer noticeable. This analysis illustrates one of the major difficulties of making
Table 2. Values of the slope coefficient $\left(\beta(\theta)_{1}\right), t$-statistic, and $p$-values for quantile regression of OND, JFM, and annual rainfall against year of record for stations where trends were significant.

\begin{tabular}{lccrc}
\hline Station & $\theta$ & $\beta(\theta)_{1}$ & $t$-statistic & $p$-value \\
\hline \multicolumn{5}{c}{ OND (Oct-Nov-Dec) } \\
\hline Hwange & 0.10 & 0.56 & 2.00 & 0.048 \\
Plumtree & 0.10 & 0.86 & 3.11 & 0.003 \\
Wedza & 0.20 & -1.63 & -2.32 & 0.023 \\
Guruve & 0.80 & -1.10 & -2.14 & 0.035 \\
Guruve & 0.90 & -2.30 & -3.16 & 0.002 \\
\hline \multicolumn{5}{c}{ JFM $($ Jan-Feb-Mar) } \\
\hline Mutare & 0.10 & -1.21 & -2.03 & 0.045 \\
Gutu & 0.20 & -2.03 & -2.83 & 0.006 \\
Gutu & 0.30 & -1.71 & -2.11 & 0.037 \\
Kadoma & 0.30 & -2.27 & -2.34 & 0.022 \\
Thuli & 0.30 & -1.19 & -2.66 & 0.009 \\
Mt Darwin & 0.30 & 1.72 & 2.08 & 0.041 \\
Buhera & 0.90 & -4.55 & -2.67 & 0.009 \\
\hline & \multicolumn{5}{c}{ Annual } & \\
\hline Guruve & 0.70 & -2.74 & -2.22 & 0.029 \\
Guruve & 0.80 & -3.41 & -2.50 & 0.014 \\
Harare & 0.80 & 2.04 & 2.37 & 0.020 \\
Harare & 0.90 & 2.06 & 2.41 & 0.018 \\
Middle Save & 0.80 & 3.69 & 2.17 & 0.033 \\
\hline & \multicolumn{5}{c}{}
\end{tabular}

inferences regarding changes of hydrological time series in that the record length may influence the conclusion made. Caution has therefore to be exercised regarding the presence of change and trends in hydrological time series particularly short time series.

Quantile regression results show that the 10th percentile of the OND rainfall increased over time at two stations, Hwange and Plumtree, while the 20th percentile decreased at one station, Wedza (Figs. 6 and 7, Table 2). A decline in the 80th and 90th percentiles of OND rainfall was detected at one station (Guruve). Some decline of 10th to 30th percentiles of JFM rainfall were identified at five stations (Figs. 6 and 8), and a change in high JFM rainfall at one station, Buhera. The 70th and 80th percentiles of the annual rainfall were identified as decreasing at one station (Guruve) on the northern part. An increasing trend of the 80th and 90th percentiles for annual rainfall at Harare was detected. (Fig. 9, Table 2).

The decline of the 20th percentile of OND rainfall was detected at one station. Four stations had significant decline in 10th, 20th and 30th percentiles of the JFM rainfall. The 80th and 90th percentiles of the OND rainfall decreased at one station, while the 90th percentile of the JFM rainfall decreased at one station. A decline in the 70th and 80th percentiles of total annual rainfall was detected at one station. The total 

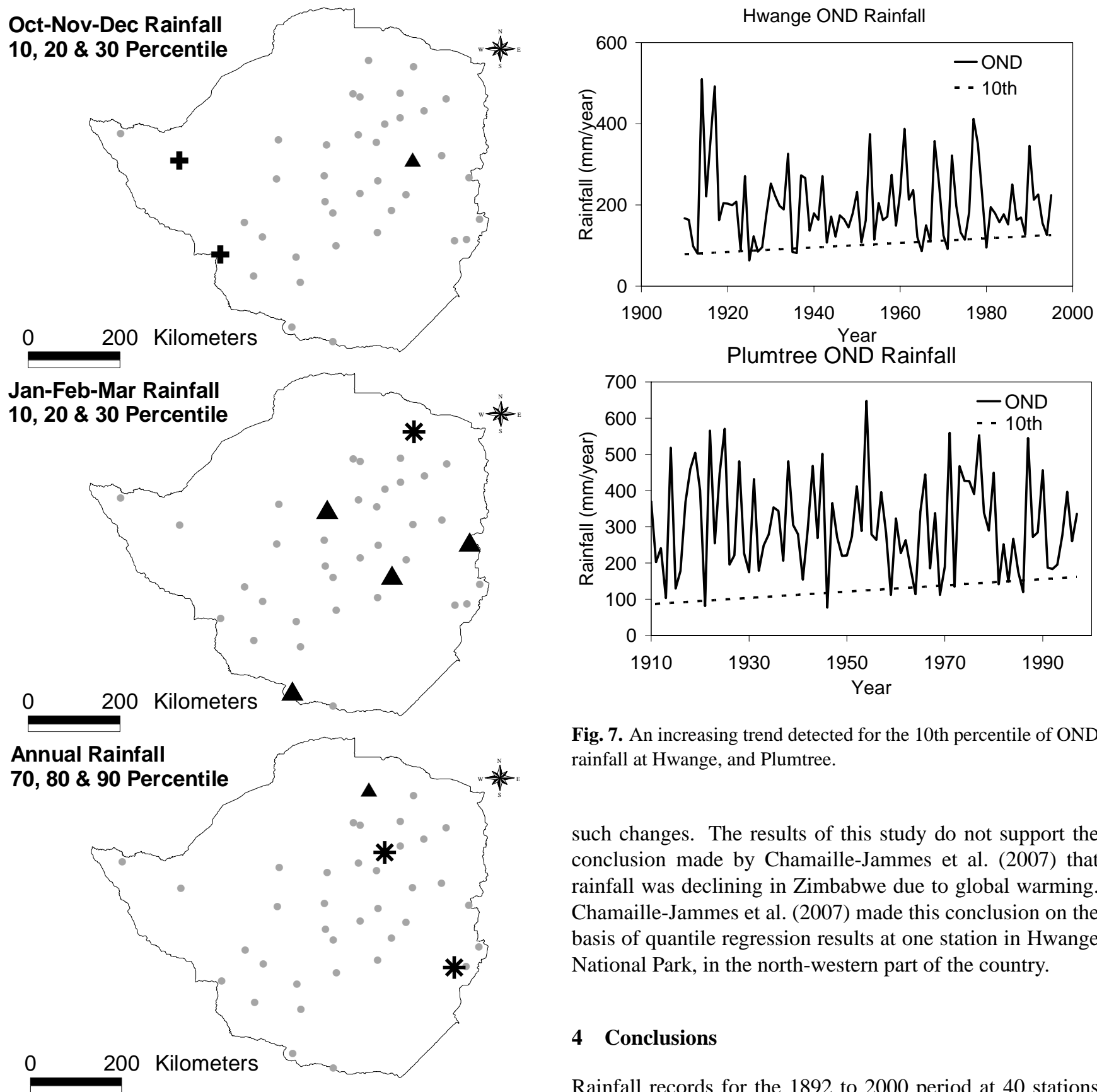

Fig. 7. An increasing trend detected for the 10th percentile of OND rainfall at Hwange, and Plumtree.

such changes. The results of this study do not support the conclusion made by Chamaille-Jammes et al. (2007) that rainfall was declining in Zimbabwe due to global warming. Chamaille-Jammes et al. (2007) made this conclusion on the basis of quantile regression results at one station in Hwange National Park, in the north-western part of the country.

\section{Conclusions}

Rainfall records for the 1892 to 2000 period at 40 stations in Zimbabwe do not demonstrate evidence of changes in the

Fig. 6. Location of stations for which quantile regression identified a decreasing (triangle) or increasing (cross or star) trend for low $(10 \%, 20 \%$, and $30 \%$ percentile) and high $(70 \%, 80 \% \& 90 \%$ percentile) rainfall.

number of stations examined in this study is 40 . Changes in percentiles have been detected at very few stations which does not provide convincing evidence that rainfall in Zimbabwe is declining due to global warming. Similarly, the evidence that high rainfall has declined is very weak, since only one station for OND and another for JFM rainfall show median, high or low rainfall during the beginning (October to December), mid-to-end (January to March) of the rainy season, and for the whole year. The very few stations which had evidence of changes of the median and some percentiles were located in different parts of the country, which is an indication that the changes identified are not likely to be physically significant but could be due to changes of the exposure of rain gauges, e.g. increase in the built up area over time. Effects of global warming on rainfall that may have occurred are not yet statistically identifiable within the available rainfall time series. Other studies in Africa and Zimbabwe (New et al., 2006; Conway et al., 2008; Aguilar et al., 2009) made the 

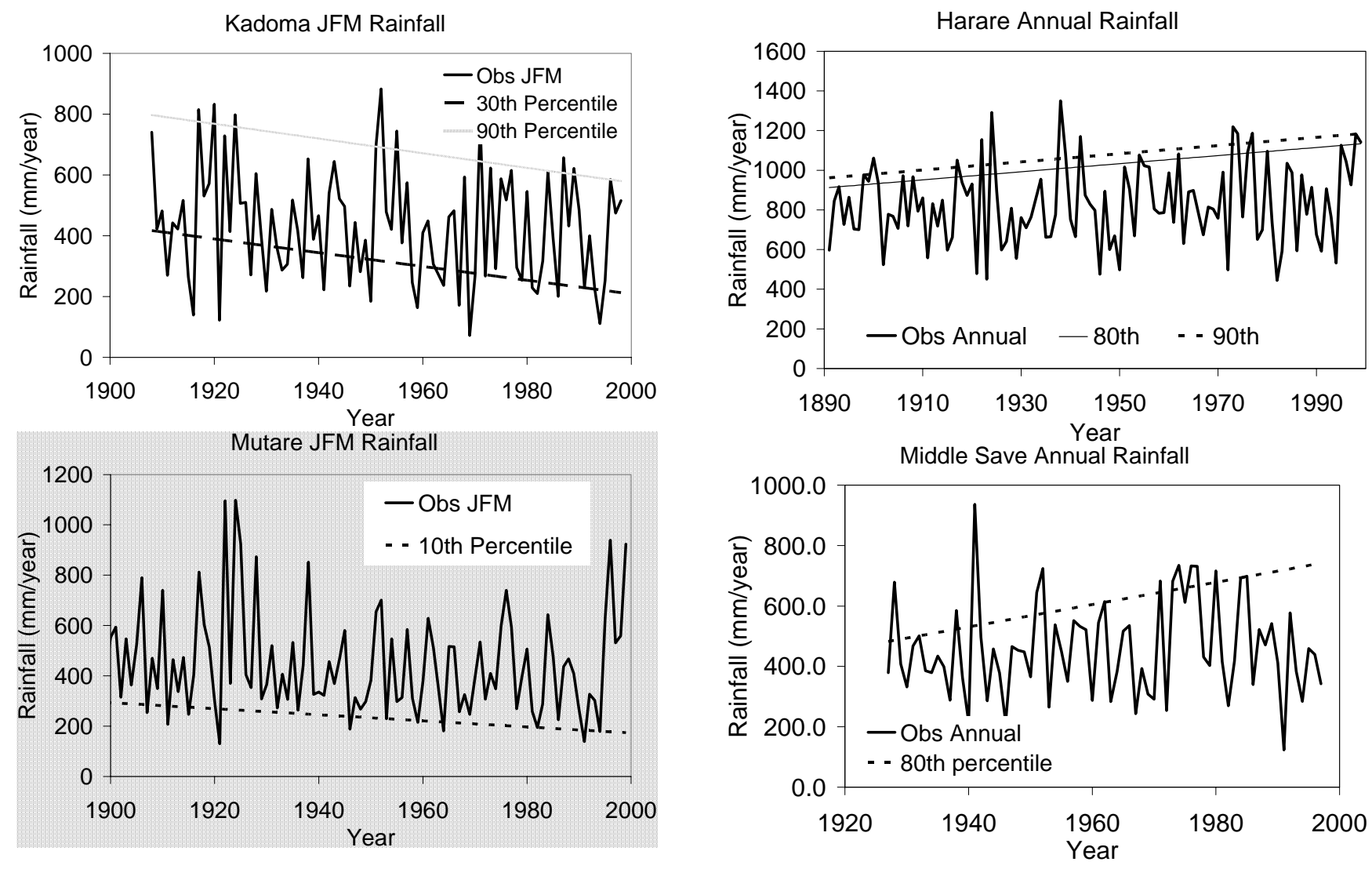

Fig. 8. A decreasing trend in the 30th and 90th percentiles at Kadoma, and 10th percentile at Mutare for the JFM rainfall.

same conclusion. This does not imply that global warming will not cause changes of rainfall in Zimbabwe, but the effects are not yet statistically significant within the available historical rainfall record. Effects of climate change on annual rainfall may not be statistically detectable due to the low signal to noise ratio arising from the high interannual variability of rainfall in Zimbabwe.

The results of this study show that the long-term average input of rainfall into the land phase of the hydrological system has not changed. However, anthropogenic changes of land use and land cover, accelerated soil erosion resulting in increased siltation rates have in some cases adversely affected the available water resources (Schulze, 2000). These adverse effects are sometimes erroneously attributed to the decline of rainfall. Human and livestock populations in southern Africa increased tremendously during the twentieth century, but with no commensurate increase in resilience against droughts and floods. Consequently, the numbers of people and livestock adversely affected by droughts and floods have been increasing which is again perceived as evidence for increasing frequency and severity of droughts. The perception about gradual desiccation can also be a symptom of an environmental nostalgia resulting in the past being considered to have been wetter than the current period.

Fig. 9. An increasing trend for the 80th and 90th percentiles of annual rainfall at Harare and 80th percentile of annual rainfall at Middle Save.

Most parts of southern Africa are semi-arid to arid with high inter-annual variability of rainfall and the available water resources. Policy makers, planners and managers of water resources systems have to accept this as a fact of this region. The challenge is to develop hydrological monitoring systems, water supply systems, and investing in the development and retention of human resources with skills for managing highly variable water resources, and therefore reduce vulnerability towards droughts and floods (Kundzewicz and Kaczmarek, 2000; Kunzewicz et al., 2002). Reducing vulnerability towards the current high variability will increase the capacity to respond to uncertainty arising from climate change. This paper recommends further studies to investigate whether daily rainfall has declined or increased at stations representative of the rainfall regions of Zimbabwe. Changes in rain gauge exposure and observational procedures may introduce noticeable decline or increase of rainfall at a station. Studies aimed at examining whether a change has occurred in rainfall time series should use several stations such as the 40 stations used in this study, so that any change which is physically significant is corroborated by similar changes at other stations within the same rainfall region. 
Acknowledgements. The author is grateful for the data provided by the Department of Meteorological Services of Zimbabwe. Comments by the editor and reviewers assisted in improving the quality of this paper.

Edited by: A. Opere

\section{References}

Aguilar, E., Aziz Barry, E., Brunet, M., Ekang, L., Fernandes, A., Massoukina, M., Mbah, J., Mhanda, A., do Nascimento, D. J., Peterson, T. C., Thamba Umba, O., Tomou, M., and Zhang, X.: 2009. Changes in temperature and precipitation extremes in wester, central Africa, Guinea Conakry, and Zimbabwe, J. Geophys. Res., 114(11p), 19552006, doi:10.1029/2008JDO11010, also available: http://www. agu.org/journals/ABS/2009/2008JD011010.shtml, 2010

Buchinsky, M.: Recent advances in quantile regression models: A practical guide for empirical research, J. Hum. Resour., 33(1), 88-126, 1998.

Cade, B. S. and Noon, B. R.: A gentle introduction to quantile regression for ecologists, Front Ecol. Environ., 1(8), 412-420, 2003.

Chamaille-Jammes, S., Fritz, H., and Murindagomo, F.: Detecting climate changes of concern in highly variable environments: Quantile regressions reveal that droughts worsen in Hwange National Park, Zimbabwe, J. Arid Environ., 71, 321-326, 2007.

Conway, D., Persechino, A., Ardoin-Bardin, S., Hamandawana, H., Deulin, C., and Mahe, G.: Rainfall and water resources variability in sub-Saharan Africa during the 20th century. Working Papaer 119, Tyndall Centre for Climate Change Research, University of East Anglia, UK, 2008.

Fauchereau, N., Trzaska, S., Rouault, M., and Richard, Y.: Rainfall Variability and Changes in Southern Africa during the 20th Century in the Global Warming Context, Natural Hazards Journal, 29(2), 139-154, 2003.

Hulme, M., Doherty, R. M., Ngara, T., New, M. G., and Lister, D.: African climate change: 1900-2100, Clim. Res., 17, 145-168, 2001.

Kendall, M.: Time series, Griffin, London, 1976.

Koenker, R.: Quantile regression in R: A vignette, http://www.econ. uiuc.edu/ $\sim$ roger/research/rq/vig.pdf, 2006.

Koenker, R. and Bassett, G.: Regression quantiles, Econometrica, 46(1), 33-50, 1978.

Koenker, R. and Hallock, K. F.: Quantile regression, J. Econ. Perspect., 15(4), 143-1456, 2001.

Kundzewicz, Z. W.: Searching for change in hydrological data, Hydrolog. Sci. J., 49(1), 3-6, 2004.

Kundzewicz, Z. W. and Kaczmarek, Z.: Coping with hydrological extremes, Water International, 25(1), 66-75, 2000.

Kundzewicz, Z. W. and Robson, A. J.: Change detection in hydrological records - a review of the methodology, Hydrol. Sci. J., 49(1), 7-19, 2004.

Kundzewicz, Z. W., Budhakooncharoen, S., Bronstert, A., Hoff, H., Lettenmaier, D., Menzel, L., and Schulze, R.: Coping with variability and change: floods and droughts, Nat. Resour. Forum, 26, 263-274, 2002.
Mason, S. J. and Jury, M. R.: Climatic variability and change over southern Africa: a reflection on underlying processes, Prog. Phys. Geog., 21(1), 23-50, 1997.

Makarau, A.: Intra-seasonal oscillatory models of the southern Africa summer circulation, Unpublished $\mathrm{PhD}$ Thesis, University of Cape Town, 1995.

Mazvimavi, D. and Wolski, P.: Long-term variations of annual flows of the Okavango and Zambezi Rivers, Physics and Chemistry of the Earth Journal, 31, 944-951, 2006.

Nash, D. J. and Endfield, G. H.: A 19th century climate chronology for the Kalahari Region of central southern Africa derived from missionary correspondence, Int. J. Climatol., 22, 821-841, 2002.

Nash, D. J. and Endfield, G. H.: Splendid rains have fallen: links between El Nino and rainfall variability in the Kalahari, 18491900. Climatic Change, 86, 257-290, 2008.

Nechval, N. A. and Nechval K. N.: Detecting a change point in a sequence of small area statistics, Statistics in Training, 4(4), 699-710, 2000.

New, M., Hewitson, B., Stephenson, D. B., Tsiga, A., Kruger, A., Manhique, A., Gomez, B., Coelho, C. A. S, Masisi, D. N., Kululanga,, Mbambalala, E., Adesina, F., Saleh, H., Kanyanga, J., Adosi, J., Bulane, L., Fortunata, L., Mdoka, M. L., and Lajoie, R.: Evidence of trends in daily climate extremes over Southern and West Africa, J. Geophys. Res., 111, 1-11, 2006.

Nicholson, S. E.: The nature of rainfall variability over Africa on time scales of decades to millennia, Global Planet. Change, 26, 137-158, 2000.

Pettitt, A. N.: A non-parametric approach to the change-point problem, Appl. Statist., 28(2), 126-135, 1979.

Radziejewski, M. and Kundzewicz, Z. W.: Detectability of changes in hydrological records, Hydrolog. Sci. J., 49(1), 39-51, 2004.

Richardson, C. J.: How much did drought matter? Linking rainfall and GDP growth in Zimbabwe, African Affairs, 106/424, 463478, 2007.

Schulze, R. E.: Modelling hydrological responses to land use and climate change: A southern African perspective, Ambio, 29(1), 12-22, 2000.

Stott, P. A, Gillett, N. P, Hegerl, G. C., Karoly, D. K, Stone, D. A., Zhang, X., and Zwiers, F.: Detection and attribution of climate change: a regional perspective, WIREs, Clim. Change, 1, 192211, 2010.

Tyson, P. D.: Climatic change and variability in southern Africa, Oxford University Press, Cape Town, 1986.

Unganai, L. S.: Historic and future climatic change in Zimbabwe, Clim. Res., 6, 137-145, 1996.

Unganai, L. S. and Mason, S. J.: Spatial characterization of Zimbabwe summer rainfall during the period 1920-1996, S. Afr. J. Sci., 97, 425-431, 2001.

Van Wageningen, A. and du Plessis, J. A.: Are rainfall intensities changing, could climate change be blamed and what could be the impact for hydrologists?, Water SA, 33(4), 571-574, 2007.

Yu. K., Lu, Z., and Stander, J.: Quantile regression: Application and current research areas, The Statistician, 52(3), 331-350, 2003. 